\title{
El trabajador del sector público: la renuncia obligatoria y la violación de los derechos laborales
}

\section{The public sector worker: mandatory resignation and violation of labor rights}

\author{
Nancy Beatriz Calle Idrovo ${ }^{1}$ \\ ${ }^{1}$ Universidad Católica de Cuenca \\ *ncalle@ucacue.edu.ec
}

DOI: https://doi.org/10.26871/killkana_social.v2i4.515

\begin{abstract}
Resumen
En la actualidad, en el Ecuador se ha implementado el Decreto Ejecutivo 813, en su artículo 8, el cual hace mención a la figura supuestamente jurídica de las "renuncias obligatorias". Esta figura jurídica es una forma totalmente arbitraria e inconstitucional como forma oficial para despedir ilegalmente a los servidores públicos. Por lo tanto, el objetivo de la investigación se enfoca en analizar la inconstitucionalidad del Decreto Ejecutivo 813 y cómo afecta a los derechos laborales de la servidora o servidor público. La metodología que se utilizó en la investigación ha sido cuali - cuantitativa, con enfoque descriptivo. El universo y la muestra estuvieron conformadas por 138 profesionales en libre ejercicio del Derecho en el cantón Cuenca, a quienes se les aplicó la técnica de la encuesta a través del cuestionario como instrumento de recolección de datos. De los resultados de la investigación de campo, se confirmó que la mayoría de los profesionales encuestados, se encuentran de acuerdo en que la disposición del Decreto Ejecutivo 813 en su artículo 8, es inconstitucional y contraria al derecho del trabajo que dispone la Constitución, lo cual les genera inseguridad jurídica en las y los servidores públicos ante la exigencia de una renuncia en forma obligatoria, que afecta a su estabilidad laboral pero también a sus ingresos económicos.
\end{abstract}

Palabras clave: sector público, derecho laboral, renuncias.

\begin{abstract}
Currently, in Ecuador, Executive Decree 813, in its article 8, has been implemented, which mentions the supposedly legal figure of "mandatory resignations". This legal figure is a totally arbitrary and unconstitutional form as an official way to illegally fire public servants. Therefore, the objective of the investigation focuses on analyzing the unconstitutionality of Executive Decree 813 and how it affects the labor rights of the public servant. The methodology used in the research has been qualitative - quantitative, with a descriptive approach. The universe and the sample were made up of 138 professionals in the free exercise of Law in the canton of Cuenca, to whom the survey technique was applied through the questionnaire as a data collection instrument. From the results of the field investigation, it was confirmed that most of the professionals surveyed agree that the provision of Executive Decree 813 in Article 8 is unconstitutional and contrary to the labor law provided by the Constitution, which generates legal uncertainty in public servants in the face of the requirement of a mandatory resignation, which affects their job stability but also their economic income.
\end{abstract}

Keywords: public sector, labor law, resignations.

\section{Introducción}

El problema detectado y que motiva el presente estudio, se encuentra enmarcado en la emisión y aplicación del Decreto Ejecutivo 813 que en su artículo 8 hace mención a la figura supuestamente jurídica de las "renuncias obligatorias", la cual, en opinión de varios expertos en la materia de Derecho Laboral, a más de su contrasentido semántico, es atentatorio a los derechos concedidos de las y los servidores públicos. De tal forma que el análisis del mismo y que culmina con la propuesta de reforma a la LOSEP, contiene los suficientes fundamentos.

En la actualidad en el Ecuador se ha implementado dicha figura jurídica como una forma totalmente arbitraria e inconstitucional como forma oficial para despedir ilegalmente a los servidores públicos librándole al Estado del pago de las indemnizaciones; con ello, no solo que se viola la normativa jurídica, sino también los principios y garantías laborales que constan en la Constitución de la República y en los instrumentos internacionales. 
De acuerdo a las cifras oficiales de la SENPLADES, se cree que hasta la fecha de nuestro estuido han salido o han sido desenrolados a través de la renuncia obligatoria unos 3.000 servidores públicos, de diversas instituciones estatales tales como: Ministerios de Salud, del Interior, de Justicia, de Desarrollo Urbano y Vivienda, de Transporte y Obras Públicas, etc.

El Decreto Ejecutivo Nro. 813, no tiene otro objetivo que, por medio de la compra de renuncias que era una expresión de la voluntad del servidor público, hacer de dicha renuncia una circunstancia obligatoria con la que se pisoteaba la ley y el derecho de las personas, mientras se aplicaba un mecanismo de movilidad burocrática a capricho del Presidente de la República, con el fin de ir llenando las vacantes con sentido clientelar, toda vez que las correspondientes partidas no se eliminaban, lo cual era el fundamento legal de la llamada compra de renuncias..

Se considera por lo tanto que el mencionado Decreto Ejecutivo 813, con el contenido exacto del artículo 8 que regula la renuncia obligatoria, a pesar de que se garantiza el pago de la indemnización correspondiente, es atentatorio, inconstitucional e ilegal, tal como lo menciona Tandazo (2015) que en su trabajo investigativo manifiesta: "violenta normas de la Constitución de la República del Ecuador, ya que se obliga a la cesación de funciones con la renuncia obligatoria, distante a la señalada en la Ley que es una renuncia con indemnización, esto va en contra de la concientización constitucional a favor de los derechos fundamentales y donde los mismos se elevan como eje central del sistema jurídico, y como sustento universal de irremediable legitimidad, gracias al limitado rol de la doctrina jurídica que permite explicar la justificación del derecho; como un proceso de constitucionalización del sistema o vida jurídica, limita el ejercicio del poder público mediante la protección de los derechos de las personas, con lo cual da la constitución un nuevo orden de valores" (Tandazo, 2015).

Por otro lado, hay que añadir que el Decreto Ejecutivo 813, en su artículo 8, no reforma la Ley, sino el Reglamento a la LOSEP y, lo que es más preocupante, a través del reglamento reforma la ley misma. Entonces, hemos de entender que para dicha reforma no se siguió el procedimiento señalado en la norma constitucional, tal como lo señala Tandazo "la Ley se determina la compra de renuncia con indemnización, que de ningún modo pueda el Estado y sus autoridades a renunciar en nombre de los servidores públicos, en la cual se está imponiendo con la renuncia obligatoria la voluntad a obligarse a renunciar a derechos, como al trabajo y a la estabilidad laboral, que por principios son irrenunciables" (Tandazo, 2015).

La compra de renuncia de forma unilateral y obligatoria, trae como consecuencia el irrespeto a la norma constitucional y legal, pues violenta la tutela jurídica de supremacía constitucional. Pues, si bien la Constitución permite que la Ley establezca la cesación de funciones a través de la renuncia con indemnización, pero en el reglamento se establece, situaciones que van más allá de lo legal y viola el principio de libre expresión de la voluntad, dando como resultado que la indicada renuncia deviene de un acto unilateral del estado que convierte lo voluntario en obligatorio, desnaturalizando así el cometido de los procesos de reestructuración, optimización o racionalización del servicio público.

Por lo expuesto, el Decreto de marras no solo se lo ha de ver como atentatorio contra los derechos constitucionales y legales de los servidores públicos, sino también como una manifestación del autoritarismo que caracterizó al gobierno de Rafael Correa Delgado, al que no le importó atentar contra los derechos de una gran masa de servidores públicos, sino que desmanteló el tejido laboral del Estado, $\mathrm{y}$ sin importar los principios de eficiencia y eficacia que deben caracterizar al aparato burocrático, llenó de personas sin la debida preparación pero que engrosaban las filas de los que se entusiasmaban con la llamada Revolución Ciudadana.

\section{Objetivo y Metodología}

Este estudio pretende realizar la elaboración de un anteproyecto de ley que deje sin efecto el Art. 47 literal "k" de la LOSEP y Art. 108 innumerado del Reglamento a la LOSEP, y se incorpore un artículo que prohíba la venta forzosa de la renuncia a los servidores públicos para garantizar el derecho a la libre expresión a la voluntad y el derecho al trabajo.

Con la emisión del Decreto Presidencial 813, el servicio público sufrió un gran revés en cuanto a la estabilidad y garantía de los derechos laborales de servidoras y servidores, los que tuvieron que renunciar sus puestos de trabajo bajo la figura de las renuncias obligatorias, totalmente inconstitucional, y sin sentido semántico Por lo tanto, el objetivo de la investigación se enfocó en analizar la inconstitucionalidad del Decreto Ejecutivo 813 y cómo afecta a los derechos laborales de la servidora o servidor público, planteando para ello un Anteproyecto reformatorio a la normativa jurídica.

La metodología que se utilizó en la investigación ha sido cuali - cuantitativa, con enfoque descriptivo. El universo y la muestra estuvieron conformadas por 138 profesionales en libre ejercicio del Derecho en el cantón Cuenca, a quienes se les aplicó la técnica de la encuesta a través del cuestionario como instrumento de recolección de datos.

Entre los principales resultados obtenidos se encuentra el que la mayoría está de acuerdo en que se derogue el Decreto Ejecutivo 813 para eliminar la figura de las renuncias obligatorias a las y los servidores públicos, puesto que el instrumento legal causa inseguridad jurídica y efectos negativos en el aspecto laboral como económico de los servidores.

\section{Desarrollo}

En la actualidad en el Ecuador se ha implementado la figura jurídica de la "renuncia obligatoria" como una 
forma totalmente arbitraria e inconstitucional para despedir a los servidores públicos, lo que es una clara violación no sólo a la normativa jurídica sino también a los principios y garantías laborales. De acuerdo a las cifras que maneja la SENPLADES, se cree que hasta la fecha han salido o han sido desenrolados a través de la renuncia obligatoria unos 3.000 servidores públicos, de diversas instituciones estatales tales como: Ministerios de Salud, del Interior, de Justicia, de Desarrollo Urbano y Vivienda, de Transporte y Obras Públicas, etc.

La Constitución de la República del Ecuador, aprobada en el año 2008 sigue las mismas propuestas garantistas que las anteriores, pero recoge entre sus disposiciones nuevos enfoques en cuanto al derecho al trabajo, al buen vivir, prohíbe la tercerización y fomenta el derecho al desarrollo económico y productivo. A continuación, se presenta un estudio sobre el contenido de la Carta Magna sobre la relación laboral, el trabajo, sus beneficios y ventajas:

Conforme al art. 327 de la carta magna, la relación laboral entre personas trabajadoras y empleadoras o entre servidores y entidades públicas contratantes, será bilateral y directa.

La misma norma prohíbe: toda forma de precarización: la intermediación laboral y la tercerización en las actividades propias y habituales de la empresa o persona empleadora, la contratación laboral por horas, o cualesquiera otra que afecte los derechos de las personas trabajadoras o servidores públicos en forma individual o colectiva. El incumplimiento de obligaciones, el fraude, la simulación, y el enriquecimiento injusto en materia laboral se penalizarán y sancionarán de acuerdo con la ley.

La remuneración, conforme al art. 328 de la constitución, será justa, con un salario digno, que cubra al menos las necesidades básicas de la persona trabajadora o un sueldo para el servidor público, así como las de su familia; será inembargable, salvo para el pago de pensiones por alimentos.

El estado fijará y revisará anualmente, el salario básico establecido en la ley, de aplicación general y obligatoria.

El pago de remuneraciones se dará en los plazos convenidos y no podrá ser disminuido ni descontado, salvo con autorización expresa de la persona trabajadoras y de acuerdo con la ley.

Lo que el empleador o entidad contratante deba a las y los trabajadoras o servidores públicos, por cualquier concepto, constituye crédito privilegiado de primera clase, con preferencia aún a los hipotecarios.

Para el pago de indemnizaciones, la remuneración comprende todo lo que perciba la persona trabajadora o servidor público en dinero, en servicios o en especies, inclusive lo que reciba por tiempos extraordinarios y suplementarios, a destajo, comisiones, participación en beneficios o cualquier otra retribución que tenga carácter normal. Se exceptuarán el porcentaje de utilidades, los viáticos o subsidios ocasionales y las remuneraciones adicionales.
Las personas trabajadoras del sector privado, tienen derechos a participar de las utilidades líquidas de las empresas, de acuerdo con la ley. La ley fijará el límite de esa participación en las empresas de explotación de recursos no renovables. En las empresas en las cuales el estado tenga participación mayoritaria, no habrá pago de utilidades. Todo fraude o falsedad en la declaración de utilidades que perjudique este derecho se sancionará por la ley.

El derecho al acceso al empleo en igualdad de condiciones, se establece en el art., 329 de la constitución, y manifiesta, que las jóvenes y los jóvenes, tendrá derecho de ser sujetos activos en la producción, así como en las labores de auto sustento, cuidado familiar e iniciativas comunitarias. Se impulsarán condiciones y oportunidades con este fin.

Para el cumplimiento del derecho al trabajo en las comunidades, pueblos y nacionalidades, el estado adoptará medidas específicas para eliminar discriminaciones que las afecten, reconocerá y apoyará sus formas de organización del trabajo, y garantizará el acceso al empleo en igualdad de condiciones.

Se reconocerá y protegerá el trabajo autónomo y por cuenta propia, realizado en espacios públicos, permitidos por la ley y otras regulaciones. Se prohíbe toda forma de confiscación de sus productos, materiales o herramientas de trabajo.

Los procesos de selección, contratación y promoción laboral se basarán en requisitos de habilidades, destrezas, formación, méritos y capacidades. Se prohíbe el uso de criterios e instrumentos discriminatorios, que afecten la privacidad, la dignidad e integridad de las personas.

El Estado impulsará la formación y capacitación para mejorar el acceso y calidad del empleo y las iniciativas de trabajo autónomo.

El Estado velará por el respeto a los derechos laborales de las y los trabajadores o servidores públicos ecuatorianos en el exterior, y promoverá convenios y acuerdos con otros países para la regularización de los mismos.

El art. 330 de la Constitución, establece que se garantizará la inserción y accesibilidad en igualdad de condiciones al trabajo remunerado de las personas con discapacidad. El estado y los empleadores implementarán servicios sociales y de ayuda especial para facilitar su actividad. Se prohíbe disminuir la remuneración del trabajador o servidor público con discapacidad por cualquier circunstancia relativa a su condición.

El art. 331 de la Carta Magna, establece que el estado garantizará a las mujeres igualdad en el acceso al empleo, a la formación y promoción laboral y profesional, a la remuneración equitativa, y a la iniciativa de trabajo autónomo. Se adoptará todas las medidas para eliminar las desigualdades.

Se prohíbe toda forma de discriminación, acoso o acto de violencia de cualquier índole, sea directa o indirecta, que afecte a las mujeres en el trabajo. 
El art. 332 manifiesta que el estado garantizará el respeto a los derechos reproductivos de las personas trabajadoras o en el servicio público, lo que incluye la eliminación de riesgos laborales que afecten la salud reproductiva, el accesos y estabilidad en el empleo sin limitaciones por embarazo o número de hijas e hijos, derechos de maternidad, lactancia y el derecho de licencia por paternidad.

Se prohíbe, el despido de la mujer trabajadora o servidora pública, asociado a su condición de gestación y maternidad, así como la discriminación vinculada con los roles reproductivos.

El Estado promoverá un régimen laboral que funcione en armonía con las necesidades del cuidado humano, que facilite servicio, infraestructura y horario de trabajo adecuados; de manera especial, proveerá servicios de cuidado infantil, de atención a las personas con discapacidad y otros necesarios para que las personas trabajadoras puedan desempeñar sus actividades laborales.

La protección de la seguridad social se extenderá de manera progresiva a las personas que tengan a su cargo el trabajo familiar no remunerado en el hogar, conforme a las condiciones generales del sistema y la ley.

La Constitución en el Título VII denominado Régimen del Buen Vivir, consta su capítulo I acerca de la inclusión y equidad, y en el parágrafo $3^{\circ}$ se refiere a la seguridad social.

Así, en su art. 367, manifiesta que el sistema de seguridad social es público y universal, no podrá privatizarse y atenderá todas las necesidades contingentes de la población. La protección de las contingencias se hará efectiva a través del seguro universal obligatorio y de sus regímenes especiales.

El sistema se guiará por los principios del sistema nacional de inclusión y equidad social y por los de obligatoriedad, suficiencia, integración, solidaridad y subsidiaridad.

En el art. 368 se establece que, el sistema de seguridad social comprenderá las entidades públicas, normas, políticas, recursos, servicios y prestaciones de seguridad social, y funcionará con base en criterios de sostenibilidad, eficiencia, celeridad y transparencia. El estado normará, regulará y controlará las actividades relacionadas con la seguridad social.

Conforme al art. 369, el seguro universal obligatorio cubrirá las contingencias de enfermedad, maternidad, paternidad, riesgo de trabajo, cesantía, desempleo, vejez, invalidez, discapacidad, muerte y aquellas que defina la ley. Las prestaciones de salud de las contingencias, de enfermedad y maternidad se brindarán a través de la red pública integral de salud.

El seguro universal obligatorio se extenderá a toda la población urbana y rural, con independencia de su situación laboral. Las prestaciones para las personas que realizan trabajo doméstico no remunerado y tareas de cuidado, se financiarán con aportes y contribuciones del estado. La ley definirá el mecanismo correspondiente.

La creación de nuevas prestaciones estará debidamente financiada.
Según el art. 371, las prestaciones de la seguridad social, se financiarán con el aporte de las personas aseguradas en relación de dependencia y de sus empleadoras y empleadores; con los aportes de las personas independientes aseguradas; con los aportes voluntarios de las ecuatorianas y ecuatorianos domiciliados en el exterior; y con los aportes y contribuciones del Estado.

Los recursos del Estado destinados para el seguro universal obligatorio, constarán cada año en el presupuesto general del estado y serán transferidos en forma oportuna.

Las prestaciones en dinero del seguro social no serán susceptibles de cesión, embargo o retención, salvo los casos de alimentos debidos por ley o de obligaciones contraídas a favor de la institución aseguradora, y estarán exentas del pago de impuestos.

La disposición transitoria vigesimoquinta, se refiere a innovaciones referentes al salario y la jubilación universal de los adultos mayores; así manifiesta, que la revisión anual del salario básico se realizará con carácter progresivo, hasta alcanzar el salario digno de acuerdo a lo dispuesto en la constitución. El salario básico tenderá a ser equivalente al costo de la canasta familiar. La jubilación universal para los adultos mayores, se aplicará de modo progresivo.

Esto es lo que en definitiva nos trae la constitución de la república, referente al derecho al trabajo y el derecho a la seguridad social.

De la Constitución de la República, se deriva en resto de cuerpos legales, de los cuales existen actualmente algunos y otros que conforme se observa de la abundante exposición que hace la carta magna, para garantizar los derechos, se habrán de dictar en el futuro una serie de leyes y reglamentos para la aplicación completa, progresiva y total de todas sus normas constitucionales.

Entre las leyes actuales, se cuenta el Código del Trabajo, que es el cuerpo legal que requiere de urgentes actualizaciones para que se ponga a la parte con los enfoques constitucionales; pues lo que hasta la presente fecha le caracteriza es una serie de reformas que le han llevado a una flexibilización que perjudica al equilibrio laboral.

Respecto de la seguridad social, existe la ley de seguro social y su reglamento, cuerpos legales, que, en futuro para ponerse acordes con los mandatos constitucionales, deben recibir si no nueva regulación normativa, nuevas leyes y reglamentos afines, que aún están por crearse y promulgarse.

De acuerdo a la LOSEP, los organismos de la administración del Talento Humano y Remuneración en el sector público son:

\section{a) Ministerio de Relaciones Laborales; y \\ b) Unidades de Administración del Talento Humano de cada entidad, institución, organismo o persona jurídica. (Asamblea Nacional, 2015a).}

Con respecto al Ministerio de Relaciones Laborales, la misma LOSEP especifica en su artículo 51 cuáles son sus competencias: 
a) Ejercer la rectoría en materia de remuneraciones del sector público, y expedir las normas técnicas correspondientes en materia de recursos humanos, conforme lo determinado en esta ley;

b) Proponer las políticas de Estado y de Gobierno, relacionadas con la administración de recursos humanos del sector público;

c) Efectuar el control en la administración central e institucional de la Función Ejecutiva mediante: inspecciones, verificaciones, supervisiones o evaluación de gestión administrativa, orientados a vigilar el estricto cumplimiento de las normas contenidas en esta ley, su reglamento general, las resoluciones del Ministerio de Relaciones Laborales y demás disposiciones conexas. De sus resultados emitirá informes a los órganos de control pertinentes, para la determinación de las responsabilidades a que hubiere lugar de ser el caso;

d) Realizar estudios técnicos relacionados a las remuneraciones e ingresos complementarios del sector público. Al efecto establecerá los consejos consultivos que fueren necesarios con las diversas instituciones del sector público para la fijación de las escalas remunerativas;

e) Elaborar y mantener actualizado el Sistema Nacional de Información y el registro de todas las servidoras, servidores, obreras y obreros del sector público, y del catastro de las instituciones, entidades, empresas y organismos del Estado y de las entidades de derecho privado en las que haya participación mayoritaria de recursos públicos, determinadas en el Artículo 3 de esta Ley;

f) Determinar la aplicación de las políticas y normas remunerativas de la administración pública regulada por esta ley y evaluar y controlar la administración central e institucional;

g) Establecer políticas nacionales y normas técnicas de capacitación, así como coordinar la ejecución de programas de formación y capacitación;

h) Requerir de las unidades de administración del talento humano de la administración central e institucional, información relacionada con el talento humano, remuneraciones e ingresos complementarios, que deberán ser remitidos en el plazo de quince días;

i) Emitir criterios sobre la aplicación de los preceptos legales en materia de remuneraciones, ingresos complementarios y talento humano del sector público, y absolver las consultas que formulen las instituciones señaladas en el Artículo 3 de esta ley;

j) Establecer métodos alternativos de intervención inmediata en las instituciones de la Función Ejecutiva, a fin de prevenir a las servidoras y servidores públicos, las consecuencias que se pueden derivar por el incumplimiento de las obligaciones de sus puestos y los deberes establecidos por la Constitución y la ley;

k) Diseñar la política pública de inclusión laboral para personas pertenecientes a pueblos y nacionalidades indígenas, afroecuatorianas y montubios; así como emi- grantes retornados. Esta política de inclusión deberá tomar en consideración los conocimientos, aptitudes y profesión, requeridas para el puesto a proveer; $y$,

1) Las demás que le asigne la Ley.

En las instituciones, entidades y organismos del sector público, sujetas al ámbito de esta ley, el porcentaje de incremento de las remuneraciones y cualquier otro beneficio que cause un egreso económico de un ejercicio a otro, como máximo, será el que determine el Ministerio de Relaciones Laborales, previo informe favorable del Ministerio de Finanzas (Asamblea Nacional, 2015a) respecto de la disponibilidad económica cuando fuere del caso.

En referencia a las Unidades de Administración del Talento Humano, la LOSEP (2015a) detalla sus atribuciones en el Art. 52, y dice:

a) Cumplir y hacer cumplir la presente ley, su reglamento general y las resoluciones del Ministerio de Relaciones Laborales, en el ámbito de su competencia;

b) Elaborar los proyectos de estatuto, normativa interna, manuales e indicadores de gestión del talento humano;

c) Elaborar el reglamento interno de administración del talento humano, con sujeción a las normas técnicas del Ministerio de Relaciones Laborales;

d) Elaborar y aplicar los manuales de descripción, valoración y clasificación de puestos institucionales, con enfoque en la gestión competencias laborales;

e) Administrar el Sistema Integrado de Desarrollo Institucional, Talento Humano y Remuneraciones;

f) Realizar bajo su responsabilidad los procesos de movimientos de personal y aplicar el régimen disciplinario, con sujeción a esta ley, su reglamento general, normas conexas y resoluciones emitidas por el Ministerio de Relaciones Laborales;

g) Mantener actualizado y aplicar obligatoriamente el Sistema Informático Integrado del Talento Humano y Remuneraciones elaborado por el Ministerio de Relaciones Laborales;

h) Estructurar la planificación anual del talento humano institucional, sobre la base de las normas técnicas emitidas por el Ministerio de Relaciones Laborales en el ámbito de su competencia;

i) Aplicar las normas técnicas emitidas por el Ministerio de Relaciones Laborales, sobre selección de personal, capacitación y desarrollo profesional con sustento en el Estatuto, Manual de Procesos de Descripción, Valoración y Clasificación de Puestos Genérico e Institucional;

j) Realizar la evaluación del desempeño una vez al año, considerando la naturaleza institucional y el servicio que prestan las servidoras y servidores a los usuarios externos e internos;

k) Asesorar y prevenir sobre la correcta aplicación de esta Ley, su Reglamento General y las normas emitidas por el Ministerio de Relaciones Laborales a las servidoras y servidores públicos de la institución; 
1) Cumplir las funciones que esta ley dispone y aquellas que le fueren delegadas por el Ministerio de Relaciones Laborales;

m) Poner en conocimiento del Ministerio de Relaciones Laborales, los casos de incumplimiento de esta Ley, su reglamento y normas conexas, por parte de las autoridades, servidoras y servidores de la institución. En el caso de los Gobiernos Autónomos Descentralizados, sus entidades y regímenes descentralizados, las respectivas Unidades de Administración del Talento Humano, reportarán el incumplimiento a la Contraloría General del Estado;

n) Participar en equipos de trabajo para la preparación de planes, programas y proyectos institucionales como responsable del desarrollo institucional, talento humano y remuneraciones;

o) Aplicar el subsistema de selección de personal para los concursos de méritos y oposición, de conformidad con la norma que expida el Ministerio de Relaciones Laborales;

p) Receptar las quejas y denuncias realizadas por la ciudadanía en contra de servidores públicos, elevar un informe a la autoridad nominadora y realizar el seguimiento oportuno;

q) Coordinar anualmente la capacitación de las y los servidores con la Red de Formación y Capacitación Continuas del Servicio Público; y,

r) Las demás establecidas en la ley, su reglamento y el ordenamiento jurídico vigente (Asamblea Nacional, Ley Orgánica del Servicio Público (LOSEP), 2015).

Cuando se produce la renuncia forzada u obligatoria, la LOSEP inmediatamente procede a llenar la vacante, de acuerdo al siguiente procedimiento señalado en los artículos 57 para la creación de puestos y 58 para los contratos ocasionales:

Art. 57.- De la creación de puestos. - El Ministerio de Relaciones Laborales aprobará la creación de puestos a solicitud de la máxima autoridad de las instituciones del sector público determinadas en el artículo 3 de esta ley, a la cual se deberá adjuntar el informe de las unidades de administración de talento humano, previo el dictamen favorable del Ministerio de Finanzas en los casos en que se afecte la masa salarial o no se cuente con los recursos necesarios.

Se exceptúan del proceso establecido en el inciso anterior los gobiernos autónomos descentralizados, sus entidades y regímenes especiales, las universidades y escuelas politécnicas públicas y las entidades sometidas al ámbito de la Ley Orgánica de Empresas Públicas (Asamblea Nacional, 2015a).

Art. 58.- De los contratos de servicios ocasionales. La suscripción de contratos de servicios ocasionales será autorizada por la autoridad nominadora, para satisfacer necesidades institucionales, previo el informe de la unidad de administración del talento humano, siempre que exista la partida presupuestaria y disponibilidad de los recursos económicos para este fin.

La contratación de personal ocasional no podrá sobrepasar el veinte por ciento de la totalidad del personal de la entidad contratante; en caso de que se superare dicho porcentaje deberá contarse con la autorización previa del Ministerio de Relaciones Laborales, estos contratos no podrán exceder de doce meses de duración o hasta que culmine el tiempo restante del ejercicio fiscal en curso. Se exceptúa de este porcentaje a aquellas instituciones u organismos de reciente creación que deban incorporar personal bajo esta modalidad, hasta que se realicen los correspondientes concursos de selección de méritos y oposición y en el caso de puestos que correspondan a proyectos de inversión o comprendidos en la escala del nivel jerárquico superior. Por su naturaleza, este tipo de contratos no generan estabilidad.

El personal que labora en el servicio público bajo esta modalidad, tendrá relación de dependencia y derecho a todos los beneficios económicos contemplados para el personal de nombramiento, con excepción de las indemnizaciones por supresión de puesto o partida o incentivos para jubilación.

Las servidoras o servidores públicos sujetos a este tipo de contrato no ingresarán a la carrera del servicio público, mientras dure su contrato.

Para las y los servidores que tuvieran suscritos este tipo de contratos, no se concederá licencias y comisiones de servicios con o sin remuneración para estudios regulares o de posgrados dentro de la jornada de trabajo, ni para prestar servicios en otra institución del Sector Público.

Este tipo de contratos, por su naturaleza, de ninguna manera representará estabilidad laboral en el mismo, ni derecho adquirido para la emisión de un nombramiento permanente, pudiendo darse por terminado en cualquier momento, lo cual podrá constar del texto de los respectivos contratos.

La remuneración mensual unificada para este tipo de contratos, será la fijada conforme a los valores y requisitos determinados para los puestos o grados establecidos en las Escalas de Remuneraciones fijadas por el Ministerio de Relaciones Laborales, el cual expedirá la normativa correspondiente.

El contrato de servicios ocasionales que no se sujete a los términos de esta Ley, será causal para la conclusión automática del mismo y originará en consecuencia la determinación de las responsabilidades administrativas, civiles o penales de conformidad con la ley.

En caso de necesidad institucional se podrá renovar por única vez el contrato de servicios ocasionales hasta por doce meses adicionales salvo el caso de puestos comprendidos en proyectos de inversión o en la escala del nivel jerárquico superior (Asamblea Nacional, Ley Orgánica del Servicio Público (LOSEP), 2015).

Lo que hasta el momento no se ha dado es la supresión de partidas originadas por la renuncia obligatoria o forzada de la o el servidor público: 
Art. 60.- De la supresión de puestos. - El proceso de supresión de puestos procederá de acuerdo a razones técnicas, funcionales y económicas de los organismos y dependencias estatales. Se realizará con la intervención de los Ministerios de Relaciones Laborales, de Finanzas; y, la institución o entidad objeto de la supresión de puestos, para las entidades del Gobierno Central.

Este proceso se llevará a cabo bajo los principios de racionalización, priorización, optimización y funcionalidad, respondiendo a instancias de diagnóstico y evaluación.

Los dictámenes de los ministerios no rigen para los Gobiernos Autónomos Descentralizados, sus entidades y regímenes especiales, universidades y escuelas politécnicas públicas; y, las sometidas al ámbito de la Ley Orgánica de Empresas Públicas.

En caso de puestos vacantes que deben ser suprimidos por las razones señaladas podrá prescindirse del dictamen del Ministerio de Finanzas.

La supresión de puesto implica la eliminación de la partida respectiva y la prohibición de crearla nuevamente durante dos años, salvo casos debidamente justificados mediante el respectivo informe técnico de la unidad de administración de talento humano.

El cambio de denominación no significa supresión del puesto. La entidad que suprima partidas, no podrá celebrar contratos ocasionales en el ejercicio fiscal en curso, en puestos de la misma denominación.

Para la supresión de puestos no se considerarán los puestos que ocupen las personas con discapacidad severa o quienes tengan a su cuidado y responsabilidad un hijo, cónyuge, conviviente en unión de hecho o progenitor con un grado severo de discapacidad, debidamente certificado por el Consejo Nacional de Discapacidades (CONADIS) (Asamblea Nacional, 2015a).

La Constitución de la República aprobada en el año 2008, menciona que el Trabajo es un derecho según consta en el Art. 33 de acuerdo al siguiente enunciado:

"Art. 33.- El trabajo es un derecho y un deber social, y un derecho económico, fuente de realización personal y base de la economía. El Estado garantizará a las personas trabajadoras el pleno respeto a su dignidad, una vida decorosa, remuneraciones y retribuciones justas y el desempeño de un trabajo saludable y libremente escogido o aceptado" (Asamblea Nacional, 2008).

De tal forma que no solo se reconoce que el trabajo es un derecho, sino también un deber social que es inherente a todos los seres humanos y que interrelaciona al Estado como garante del cumplimiento de este derecho, para que la o el trabajador o servidor público tenga plena seguridad de que el desarrollo de su actividad laboral será realizada bajo la confianza de que su esfuerzo será reconocido y garantizado, siempre que este se encuentre dentro de lo que es la legalidad y lo lícito.

Además, la misma Carta Constitucional dispone que el fomento de las actividades productivas y económicas también se encuentran garantizadas, para de esta forma brindar la seguridad a toda la colectividad, de que el desarrollo del trabajo no se limita a una sola parte, sino que su acceso y la libertad de su decisión está determinada en forma igualitaria y equitativa, tal como lo especifica la vigente normativa en su parte del Buen Vivir, tema que a continuación se pasará a ser analizado.

\section{Conclusiones}

La Constitución de la República garantiza el trabajo como un derecho inherente a toda persona, sea tanto en el sector público como privado, resaltando el valor de que este derecho es intangible e irrenunciable, por lo que no se puede obligar a ningún trabajador o trabajadores, servidor o servidora, a que renuncie obligatoriamente bajo ninguna forma de cesación contraria a lo que estipula la Carta Magna, de tal forma que toda disposición en contra es inconstitucional.

El Decreto Ejecutivo 813 en el contenido del artículo 8 en el cual se menciona la compra de renuncias en forma obligatoria, va en contra de la voluntad de la servidora o servidor público, ya que como se mencionó anteriormente, la disposición va en contra de los mismos derechos que las leyes internas e internacionales otorgan a todos los mismos.

La renuncia de todo servidor o servidora, solo puede ser la expresión de su voluntad, jamás en un estado de derechos y justicia puede establecerse la violación de la intangibilidad y de irrenunciabilidad, sin que ello no esté en contraposición con la propia constitución y los instrumentos internacionales.

La LOSEP tiene como función principal regular el sistema laboral de la servidora o servidor público, validando los derechos reconocidos en la Constitución de la República, siendo por lo tanto que los derechos de los mismos no son contrarios a lo que estipula la Carta Magna, de tal forma que si se persiste en mantener vigente el Decreto 813 con respecto a las renuncias obligatorias, se están directamente violentando el derecho al trabajo, a la estabilidad laboral y la vida digna de los servidores públicos ecuatorianos.

De los resultados de la investigación de campo, se ha podido confirmar que la mayoría de los profesionales encuestados, se encuentran de acuerdo en que la disposición del Decreto Ejecutivo 813 en su artículo 8, es inconstitucional y contraria al derecho del trabajo que dispone la Constitución, generando inseguridad jurídica en las y los servidores públicos ante la exigencia de una renuncia en forma obligatoria, lo que afecta a su estabilidad laboral pero también a sus ingresos económicos, con ello se está creando un precedente que se interpreta como regresivo a los derechos que en materia laboral se han alcanzado en las últimas décadas a nivel nacional e internacional.

\section{Referencias Bibliográficas}

Acosta, A. (2008). El Buen Vivir, una oportunidad por construir. Ecuador Debate, 33-48. 
Alva Chinchilla, M., Rey, A., M. (2012). Formas de Manifestación de la Voluntad. Managua, Guatemala: Facultad de Ciencias Jurídicas y Sociales.

Asamblea Nacional. (2008). Constitución de la República del Ecuador. Quito, Pichincha, Ecuador: Editora Nacional.

Asamblea Nacional. (2010a). Ley Orgánica del Servicio Público. Quito, Pichincha, Ecuador: Registro Oficial.

Asamblea Nacional. (2010b). Ley Orgánica del Servicio Público (LOSEP). Quito: Registro Oficial Suplemento Segundo No. 294 del 6 de octubre de 2010.

Asamblea Nacional. (2015a). Ley Orgánica del Servicio Público (LOSEP). Quito: Registro Oficial Suplemento Segundo No. 294 del 6 de octubre de 2010.

Asamblea Nacional. (2015b). Ley Orgánica para la Justicia Laboral y Reconocimiento del Trabajo en el Hogar. Quito, Pichincha, Ecuador: Imprenta Nacional.

Bejarano, D. E. (2014). Configuración de desviación de poder en los actos administrativos de cesación de funciones deservidoras/es públicos por compra de de renuncia obligatoria. Quito, Pichincha, Ecuador: Universidad Central del Ecuador.

Benavides, A. (2008). Manual práctico de contratación Laboral. Valladolid: Editorial Lex Nova.

Cabanellas, G. (2010). Diccionario Jurídico Elemental. Buenos Aires: Heliasta.

Congreso Nacional. (2005a). Codificación del Código del Trabajo. Quito, Pichincha, Ecuador: Editora Nacional.

Congreso Nacional. (2005b). Ley de Funcionarios Pùblicos o empleados de confianza. Ley No. 28175. Perú.

Cueva, N. (2013). El decreto 813 y sus repercusiones en los servidores públicos del Ecuador- proyecto de reforma a la Losep. Loja, Loja, Ecuador: Universidad Nacional de Loja.

Farfán, M. (2015). Mandato de Renuncia Voluntaria en Ecuador. Universidad San Gregorio de Portoviejo. Dialnet., 1(9), 76-83.

Gajardo, M. C. (2010). Buena Fe y Derecho del Trabajo. Revista Chilena de Derecho del Trabajo y de la Seguridad Social, 1(2), 15-31.

García, A. (2014). Ineficacia de los contratos por vicios de la voluntad. Madrid, España: Universidad Pontificia.

Hernández Guerra, D., K. (2012). El principio de autonomía de la voluntad contractual civil. Sus límites y limitaciones. REJIE: Revista Jurídica de Investigación e Innovación Educativa(6), 27-46.

Hidalgo, G. (2008). Apuntes de Derecho Laboral Ecuatoriano. Teoría y Práctica. Quito: FLACSO.

Lastra, J. M. (2003). Paradojas de la autonomía de la voluntad en las relaciones de trabajo. Revista de Derecho Privado, 2(5), 109-136.

López, R. (2013). Necesidad de derogar el decreto ejecutivo 813, ante la inconstitucionalidad de la compra de renuncia obligatoria con indemnización, establecida en la losep del sector público. Loja, Loja, Ecuador: Universidad Nacional de Loja.

Mejía, P. (2012). La Constitución de la República del Ecuador y el Artículo 8 del Decreto Ejecutivo 813 en la ciudad de Babahoyo en el año 2011. Babahoyo, Ecuador: Universidad Técnica de Babahoyo.

Núñez, M. (2007). Implicaciones de la aplicación del principio de autonomía de la voluntad en el comercio internacional. Quito, Pichincha, Ecuador: Universidad Andina Simón Bolívar.

Obregón, I. (2015). El decreto ejecutivo 813 y su impacto en el desarrollo económico de los servidores del Ministerio de Inclusión Económica y Social desenrolados en el año 2012. Ambato, Ecuador: UNIANDES.

Ossorio, M. (2010). Diccionario de Ciencias Jurídicas, Políticas y Sociales. Managua: Datascam.

Pantoja, R. (2007). Los funcionarios públicos como sujetos de Derecho Administrativo. Santiago de Chile, Chile: Escuela sindical.

Presidencia de la República. (2011a). Decreto Ejecutivo 813. Quito, Pichincha, Ecuador: Editora Nacional.

Presidencia de la República. (2011b). Decreto Ejecutivo No. 710 del Reglamento General a la Ley Orgánica del Servicio Público. Quito, Pichincha, Ecuador: Editora Nacional.

Presidencia República Argentina. (1999). Régimen Jurídico Básico de la Función Pública. Buenos Aires, Argentina: UNSL.

Rivadeneyra, M. J. (2013). Las compras de renuncias obligatorias originadas por la reforma al reglamento de la ley orgánica del servicio público, aprobadas mediante decreto ejecutivo 813 del año 2011 y sus efectos en la comunidad nacional. Quito, Pichincha, Ecuador: Universidad de Las Américas.

Rubio, A. (2002). Manual de Derechos, Obligaciones y Responsabilidades en la prevención de riesgos laborales. Madrid: Fundación Confemetal.

SENPLADES. (2015). Plan Nacional para el Buen Vivir 2009-2013. Descargado de http://www.plan . senplades.gob.ec

Solano, F. (2013). Necesidad de derogar el decreto ejecutivo 813, ante la inconstitucionalidad de la compra de renuncia obligatoria con indemnización, establecida en la Losep del sector público. Loja, Loja, Ecuador: Universidad Nacional de Loja.

Suárez, A. (2015). Estudio Jurídico al Capítulo X del Código del Trabajo del Ar. 192.- Efectos del cambio de ocupación actual sin su consentimiento. Necesidad de Reformar. Loja, Loja, Ecuador: Universidad Nacional de Loja.

Tandazo, J. A. (2015). La inconstitucionalidad del decreto ejecutivo 813 aplicado a los servidores públicos ha violentado los preceptos establecidos en la Constitución de la República del Ecuador. Loja, Loja, Ecuador: Universidad Nacional de Loja. 
Ugarde, J. L. (2004). El nuevo Derecho del Trabajo. Santiago de Chile: Editorial Universitaria S.A.

Recibido: 10 de julio de 2018

Aceptado: 14 de diciembre de 2018 
